\title{
DEMANDA Y UTILIZACION DE TECNICOS EN LA INDUSTRIA COLOMBIANA, 1981
}

El estudio analiza la incorporación a las empresas de los principales centros industriales del país de los bachilleres industriales formados en los Institutos Técnicos y en los INEM y determina las ocupaciones específicas que desempeñan esos bachilleres en la producción industrial.

Los diversos capítulos especifican seis aspectos principales en relación con los planteamientos generales del estudio:

1. Niveles de calificación de los trabajadores según la asignación que les da la empresa en las principales categorías ocupacionales de profesionales, técnicos, empleados, obreros calificados, obreros no calificados y personal de servicio.

2. La distribución del personal calificado y no calificado en la estructura ocupacional de la empresa.

3. Los niveles educativos de la fuerza de trabajo industrial y la sustitución profesional que, en relación con un mismo grupo ocupacional y un mismo nivel de salarios, se produce entre trabajadores con igual grado de educación formal.

4. Entrenamiento y capacitación que recibe la población trabajadora.

5. Estimaciones de la oferta y demanda de técnicos.

6. Características sociales, profesionales y ocupacionales de los bachilleres técnicos egresados de institutos técnicos industriales y de la rama industrial de los Institutos de Enseñanza Media Diversificada.

El Capítulo II está dedicado a un análisis general del desarrollo de la industria en Colombia en la década del 70, destacando tres aspectos básicos:

1. La participación de la industria en la estructura económica tanto en la formación del producto interno bruto como en la generación del empleo.

2. Principales características internas del sector y los cambios producidos en las diferentes ramas industriales.

3. Indicadores del crecimiento total del empleo industrial y la distribución especial del mismo.

El estudio se realizó en ocho áreas metropolitanas de Colombia: Bogotá-Soacha; Medellín-Valle de Aburrá; Manizales-Villamaría; Barranquilla-Soledad; BucaramangaGirón-Florida; Pereira-Santa Rosa - Dosquebradas y Cartagena. La muestra cubrió 235 establecimientos de los sectores más modernos de la economía colombiana y un monto total de 2.654 trabajadores entre profesionales, técnicos, bachilleres técnicos y obreros calificados.

La información se obtuvo mediante la aplicación de cuestionarios a empresarios y trabajadores. 
El estudio destaca entre otras conclusiones, la existencia de grandes diferencias de salarios para un mismo oficio; diferencias en la ubicación de los trabajadores en las categorías ocupacionales de la empresa y muy distintos niveles de escolaridad en igualdad de salarios y ocupación. Dentro de esta situación los bachilleres industriales se dispersan dentro de la estructura de la empresa y la incorporación parece estar guiada más por el azar que por una lógica que prestara atención a un personal calificado por el sistema educativo para un mejor desempeño ocupacional.

Indudablemente, el estudio constituirá un valioso aporte a los planificadores de recursos humanos.

\section{SEMINARIO INTERAMERICANO SOBRE NUCLEARIZACION Y REGIONALIZACION EDUCATIVA}

Entre el 4 y 7 de noviembre del presente año, se realizó en Bogotá el Seminario Interamericano sobre Nuclearización y Regionalización Educativa, certamen al cual se hicieron presentes representantes de once países latinoamericanos: El Salvador, Nicaragua, Costa Rica, Guatemala, Panamá, Ecuador, Perú, Chile, Uruguay, Paraguay y Colombia y funcionarios del Instituto Centroamericano de Administración y Supervisión Educativa - ICASE-, del Centro Interamericano de Estudios e Investigaciones para el Planeamiento de la Educación —CINTERPLAN- y el Departamento de Asuntos Educativos de la OEA.

Este importante evento, producto de la Undécima Reunión del Consejo Interamericano para la Educación, la Ciencia y la Cultura (CIECC) realizada en julio de 1980, elaboró un programa conjunto de seminarios y pasantías que permitió conocer previamente en terreno por parte de los participantes, las experiencias de nuclearización y regionalización educativas en cada país e inmediatamente en el Seminario dar un tratamiento analítico y reflexivo a esta temática.

Reconociendo los principales problemas que a nivel latinoamericano se vienen presentando en el campo de la educación, como la necesidad de descentralizar el manejo administrativo, aumentar los niveles de retención escolar, mejorar los aspectos cualitativos en los programas de enseñanza, la capacitación docente, etc., atender a las desigualdades regionales contemplando los casos de mayor marginalidad y extrema pobreza, hacen partícipe a la población de los problemas y necesidades educativas, los programas de nuclearización apuntando a cada uno de ellos, han hecho énfasis en cada país en aspectos diferentes.

En el caso de NICARAGUA, la nuclearización se ha enfocado preferencialmente y como necesidad actual a la capacitación docente aprovechando la integración de centros docentes; en COSTA RICA el énfasis está dado hacia la educación curricular integrando a las unidades didácticas la problemática social económica; en ECUADOR el trabajo de organización y promoción de la comunidad cobra la mayor importancia y en COLOMBIA la descentralización administrativa a nivel de base asume el factor central.

En el campo de la Regionalización, la experiencia chilena fue presentada como una respuesta a las necesidades detectadas por el Mapa de extrema pobreza y como un planteamiento novedoso de descentralización administrativa a través de las municipalidades. 